\title{
Study On the Background of Differentiated Postgraduate Education in China
}

\author{
Xing Ying \\ School of Management University Of Jinan, \\ Jinan, ,China \\ e-mail:Sm_xingy@ujn.edu.cn
}

\author{
Yue Feifei \\ School of Management University Of Jinan, \\ Jinan, ,China \\ e-mail:Sm_yueff@ujn.edu.cn
}

\author{
Li Lihua \\ School of Management University Of Jinan, Jinan, ,China \\ e-mail:Sm_lilh@ujn.edu.cn
}

\begin{abstract}
This paper analyze the international implementation of differentiated education exemplified by Japan, United State and France, then analyze the differentiation of teaching resources and culture of colleges and universities in China, as well as the quality, character, background and occupation objective of students. Because of the current situation, it's urgent to implement the differentiated postgraduate education in China.
\end{abstract}

\section{background}

Keywords: Postgraduate Education, differentiated teaching,

\section{INTRODUCTION}

China's higher education has cultivate a large number o $\mathrm{f}$ talent for decades, however, the disadvantages has appe ared during the up and downs of the implementation of high er education, especially at the local colleges and universities. Under the control of rigid management system, there is a lo $\mathrm{t}$ of problem in the aspects of teaching mode, cultivate meth od, education objective and so on. Yet the most serious one which has waste a lot of teaching resources is the all- in- on e training mode, it reduce the quality of higher education an $\mathrm{d}$ this the reason why differentiated education has to be esta blished urgently. Differentiated education is a method to cul tivate high quality student in line with the market demand ac cording to different culture and teaching goals. The core phi losophy of it is to take the most suitable method according $\mathrm{t}$ o students' personality and behavior

\section{INTERNATIONAL STATUS TO IMPLEMENT DIFFERENTIATED POSTGRADUATE EDUCATION}

Every country has it's character in the implementation of differentiated education because of the different historical habit, developing process and fundamental realities. Genera lly speaking, there are two types: one is the standardized edu cation emphasizes uniform on the solid system of profession al model, this type of education has no sense of individual a ptitude and the profound of differentiated teaching; the other one is differentiated education admit individual personality represented by America, which enhance the overall ability a nd individual development of the student by the way of diffe rentiated education.

But no matter what kinds of education mode the countr $y$ applied, the importance of differentiated education has bee $\mathrm{n}$ recognized widely. Japan is the typical case of oriental cul ture emphasizes uniform teaching instead of individual char acteristics. Japan implement unified education mode for a lo ng time until 70's of 20century, they recognized the disadva ntage of unified form and began to carry out the education $r$ eform, which take the students' character as the primary prin cipal.

America emphasis on personality development for the 1 ong-standing, which paid much attention in the field of educ ation since second world war. America implements different iated education reflects in several aspects: choosing mechani sm acknowledge differences of student; talent culture mecha nism with personality; management mechanism and evaluati on method based on differentiation; differentiated goals bet ween different tape of colleges; optional courses setting by moderately common basis, etc.

France also provided several chooses which brings a go od inspiration of "phases education" learning mode for the st udents with different development processes. Regardless of the manifestation of countries differentiated education, it ha $\mathrm{s}$ the common aspect. First, the basic concept of this mechan ism is to respect students personality; second, differentiated postgraduate education is the unity of universality and indivi duality, for example, Unite States encourage differentiated a cademic objective between colleges but strengthen universal ity in students personal values and fundamental curriculum; third, it is the key point in this education mechanism to culti vate students' comprehensive ability.

\section{BACKGROUND OF IMPLEMENTING DIFFERENTIATED POSTGRADUATE EDUCATION IN CHINA}

In spite of a large number of colleges and universiti es in China, they differ in postgraduate education in many as pects, and they are basically similar in training

programs of postgraduate education and teaching content. T his similarity can avoid unnecessary mistakes, relatively reduce the cost of design and education, but with the extensive presence of similarity, higher colleges and univer sities fail to cultivate postgraduates that meet market dema nd, achieve better or best results, and students cannot develo p personal core competitiveness or forge school's core comp etitiveness, so that they are not widely recognized and accep ted by society. Thus, it is of great significance to adopt diffe rentiated education to cultivate postgraduates of personal competitiveness that meet market demand. 
The following differences should be taken into account in postgraduate education.

\section{A. Differences between schools}

Differences between schools can be mainly reflected in two aspects. Firstly, it comes to the differences in resourc es available to schools. In China, in spite of a large number of colleges and universities, they are greatly different in leve ls (non-key universities colleges and key colleges and unive rsities), affiliation (central and local), and locations. Besides , the differences the overall quality of college students is ob vious. All these factors result in the difference in a variety o $f$ resources available to different institutions of higher learni ng, among which the greatest resource is undoubtedly fundi ng and teacher resources. Due to the differentiated sources o f schools, students studying in different universities will diff er in the level of professional knowledge. The difference in $t$ he quantity and quality of knowledge acquired and other diff erences can be distinguished and evaluated through the quan titative measure of examination, and most of these differenc es can be narrowed through individual efforts. But a small $p$ art of the differences due to the effect and accumulation of $s$ elf-organizing systems of knowledge is still relatively fixed on individual students.

Secondly, it comes to the difference in the accumulatio $\mathrm{n}$ of spirit in historical development of the school. Yu Jingti an held that one difference between students in different sch ools will have lifelong impact on them and it is difficult to $\mathrm{c}$ hange it by relying on their individual consciousness. It is th e impact of ethos unique to each school (that is what called "atmosphere" by someone) on students. This ethos determin es the value, self-positioning and effort direction of universit $y$, the soul of the university, a taste of college, and it is what makes a university distinguished from other universities in $\mathrm{d}$ eeper spiritual level. (2004, Yu Jingtian)

As for local colleges and universities with limited re sources and financial constraints, they are subject to slow fl ow of information due to the distance from information cent er, and they are not advantageous in the quantity and quality of students. In this context, they should have clear self-posit ioning and clear training objectives, to address the issue o f market demand and long-term school development.

\section{B. Differences between students}

As the saying goes, no two leaves are exactly the sa me in the word. The postgraduates admitted to the same inst itution of higher learning also differ in various aspects, espe cially in the following three aspects.

\section{1) Difference in overall quality}

The differences of institutions of higher learning in res ources available directly results in their difference in attracti veness to students. Institutions of higher learning with more resources attract more high-level students, while many local colleges and universities, especially those not listed in211

Project, have narrow choice which even cannot meet thei $r$ predetermined quota ofstudents. Importantly, the autonom $\mathrm{y}$ of college admissions is poor. Especially postgraduate ad mission, to a large extent, depends on the specialized entran ce examination nationally organized. To train qualified and even excellent postgraduate that meet the market demand, it is most important to be concerned with integrated high-quali ty training objectives of self-development, a strong sense of innovation, and adaptability. The traditional course learning and examination results are not representative of the overall quality of a person, nor is it an important training objectiv $\mathrm{e}$ at this stage. The selection is out of line with training obje ctives. In this unsatisfactory situation, the big difference the overall quality of postgraduates admitted to institutions of hi gher learning will exert impact on their subsequent teaching and training programs.

\section{2) Difference in Background}

Background here mainly refers to the professional back ground. As for postgraduates, they are likely to change thei $\mathrm{r}$ undergraduate majors at the postgraduate level for many re asons, such as employment, admission rate, interest and oth er factors. These factors will lead to changes in their learnin $\mathrm{g}$ orientation. Because of a relatively low requirement for sy stematic and accumulation, it is quite common for postgradu ate candidates to apply for trans-disciplinary majors, especia lly in the graduate schools of social science, which leads $t$ o a big difference of social science postgraduates in professi onal background. Different professional backgrounds will in evitably affect students' logical thinking ability, overall gras $\mathrm{p}$ of knowledge, subsequent understanding of the courses, $\mathrm{s}$ $\mathrm{o}$ the teaching requirements are different.

3) Difference in career goal

As for postgraduates, especially those admitted to local colleges and universities, it is very important for them make a career planning, and establish their career goals soon after their admission to graduate school.

The western developed country detailed the training ob jectives and have a excellent postgraduate training mode of social sciences; however colleges in our country follow the $\mathrm{s}$ ame pattern of social sciences in teaching mode and curricul um setting, it pay much attention on the research of theories instead of the setting and effect of practice courses. All the $t$ roubles among our colleges finally influence the quality of $t$ alents training, especially in local higher educational institut ion, cut down the students adaptability to social and market,

With the continues expansion of postgraduate scale, the central element and quality of the once elite education has $\mathrm{c}$ hanged, as well as the requirement from society. Therefore, except the graduate student who prepare for a $\mathrm{PhD}$, graduate education should pay attention on the training that accessibl e to social practice department and meet the requirement of $t$ he market with the diversified vocational target.

\section{4) personality difference}

Character is the sum of a person's unique psychologica 1 characteristics, a relatively stable individual characteristics to formed in the life. It decide the fate of individual and aff ects human behavior, as well as one's occupation ability, an $\mathrm{d}$ also affect the acceptability of different mode of education 
students. The character can be classified by many angles, a nd the most important classification is the divided students $\mathrm{f}$ rom introversion and extroversion, this classification is main ly based on the human psychological activity whether inclin ed to the inner world or have enough interest on the outside world. Character has no directly related to a person's ability, IQ, social value or one's success, but the character differenc es can have a great influence on people's life.?As a universit y educator, our mission is to improve students' innovative ab ility and practical ability, strengthen students' advantages an $\mathrm{d}$ avoid its' week point, based on its' personality and charact eristics.

Therefore, higher education must understand the differ ences, acknowledge the differences in the training of postgra duate students, and take the differentiated teaching methods which has the character of flexibility and consistent with the students characteristics. As a higher educator, we have the mission to cultivate the students with the ability to adapt ma rket demand and the development potential .

\section{REFERENCES}

[1] Chen Shaoxiong, Wang Jingyi, Yin Liuyin. A Study of Charact eristics of GraduateEducation in U.S., Britain, Germany and J apan. Journal of Foshan University,May, 2004 ,pp.89-93

[2] Ma Hui. Education Reform Will Enter A Transition Year . Http: //www.wabei.com/news/200812/176717.html.

[3] Wu Rongshun. Foreign Training Modes, Characteristics and En lightenment of SocialScience Postgraduate. Journal of Yan gzhou University (Higher Education Edition), June,2008 ,p p.81-84

[4] Wang Qihua, Lu Xianliang. Innovative Education and Postgrad uate Training. Journal ofUniversity of Electronic Technolog y (Social Science Edition), February,2002 ,pp.95-98

[5] Yu Jingtian. Analysis of Key Issues of Improving China Higher Education Quality throughthe Comparison between China an $\mathrm{d}$ America. Journal of National Academy of Education Admin istration,January, 2004 ,pp.57-60 